\title{
LOS DESASTRES NATURALES Y LA GEOGRAFÍA CONTEMPORÁNEA
}

POR

\author{
ANTONIO BUJ BUJ
}

En diciembre de 1989 la Organización de Naciones Unidas declaró la presente década Decenio Internacional para la Reducción de los Desastres Naturales. La declaración tenía como objetivo promover investigaciones y acciones internacionales para reducir las pérdidas de vidas humanas, los daños materiales y los costes económicos y sociales que se producen como consecuencia de las calamidades naturales. Entre las mismas se incluyeron los terremotos, las inundaciones, los ciclones, las sequías, las erupciones volcánicas y las plagas de langosta.

No es la primera vez que la comunidad internacional desarrolla una iniciativa semejante. La Sociedad de Naciones apadrinó ya en la tercera década del presente siglo un proyecto que significó la puesta en marcha de la Unión internacional de Socorro y de un atlas universal de los eventos calamitosos. La celebración de la primera Conferencia internacional contra las calamidades naturales, en setiembre de 1937 en París, fue la culminación de ese proceso. En la reunión tuvo un papel destacado el geógrafo Raoul Montandon, animador desde la Société de Géographie de Ginebra de la revista Matériaux pour l'Étude des Calamités, cuyo primer número había aparecido en 1924. Sin embargo, otra calamidad, la guerra, acabó con la Sociedad de Naciones y en buena medida con la incipiente geografía de las calamidades.

Antonio Buj Buj. Instituto Enseñanza Secundaria «Doctor Puigvert» 
Los efectos de los desastres naturales se han dejado sentir a lo largo de toda la historia; sin embargo, no provocaron ninguna iniciativa como las anteriores. Cabe preguntarse cómo surgió esa nueva preocupación global, y también de qué manera ha conseguido plasmarse institucionalmente. Un elemento explicativo, aunque evidente, no puede dejar de mencionarse; la existencia misma de aquellas organizaciones supranacionales ha propiciado ese tipo de iniciativas. Por otro lado, el reconocimiento de que algunas calamidades, entre ellas las enfermedades epidémicas o las plagas de insectos, no respetaban frontera alguna, hizo que determinadas disciplinas científicas asentasen sus actividades desde presupuestos geográficos cada vez más universales ${ }^{1}$. Esto tuvo lugar en el tránsito del siglo XIX al xx, en el contexto del dominio imperialista europeo. La necesidad de superar aquellos escollos biológicos en regiones del planeta todavía vírgenes a la civilización occidental, en especial Africa, sirvió a la política eurocéntrica ${ }^{2}$, pero al mismo tiempo contribuyó a la realización de programas científico-técnicos de carácter universal, como el de la lucha contra las calamidades naturales, ya en nuestra centuria. Otros desastres naturales, entre ellos la erupción volcánica del Krakatoa de agosto de 1883, con 36.000 víctimas mortales, la intensa sequía en la India británica durante el bienio 1896-1897, con unos cinco millones de víctimas del hambre y las enfermedades, o el terremoto en la ciudad italiana de Mesina en 1908, con 120.000 muertos, tuvieron un fuerte impacto no sólo entre la comunidad científica, y crearon una nueva sensibilidad hacia las calamidades naturales.

Por lo que se refiere a la ciencia, la geografía europea, vinculada también con el proceso colonial a lo largo de toda la segunda mitad del siglo XIx, en el último tramo de la centuria, al plantearse una nueva batalla por su definición como disciplina, encontró renovados criterios epistemológicos en las reflexiones que sobre las relaciones en-

1 Por ejemplo, la entomología aplicada sólo pudo avanzar a partir del momento en que se internacionalizó. Véase, Leland O. Howard: A history of applied entomology (somewhat anecdotal), Washington, Smithsonian Institution, Smithsonian Miscellaneous Collections, vol. 84, noviembre 1930 , VIII-564 pp. Para las plagas de langosta véase, Antonio Buj: El Estado y el control de plagas agricolas. La lucha contra la langosta en la España contemporánea, Madrid, Ministerio de Agricultura, Pesca y Alimentación, 1996, $348 \mathrm{pp}$.

2 Daniel R. Headrick: Los instrumentos del Imperio. Tecnología e imperialismo europeo en el siglo XIX, Madrid, Alianza, 1989, 187 pp. 
tre el medio y el hombre le brindaba la naciente ecología. Algunas décadas más tarde, la disciplina pudo integrar a los eventos calamitosos en sus debates sobre el medio natural, dentro de la denominada geografía de las calamidades, cuya primera formulación aparecía en el Congreso internacional de Geografía de El Cairo, en 1925, de la mano del ya citado Raoul Montandon. Por otro lado, en Norteamérica, donde la obra de G. Perkins Marsh había inaugurado ya una línea de reflexión medioambientalista, la teoría ecológica se difundió ampliamente con el cambio de siglo. Esta tuvo un gran interés para la geografía de aquel país desde el momento en que Harlan H. Barrows definió la disciplina como una ecología humana ${ }^{3}$. Gilbert F. White, alumno suyo en la Universidad de Chicago, emprendió una línea de trabajo dentro de la llamada geografía de los recursos naturales, en contacto directo con los problemas de la gestión del agua. En la década de los sesenta, algunas de las preocupaciones del grupo formado en torno a White derivaron hacia lo que más tarde se conoció como geografía de los riesgos. Esta escuela consiguió enajenar de la nueva disciplina, por razones no estrictamente científicas, toda la tradición epistemológica no angloamericana. Las críticas, sin embargo, empezaron pronto a florecer. En ese marco debe entenderse la aparición de la geografía radical de los riesgos naturales, consistente en aplicar el análisis marxista a la comprensión de los eventos calamitosos; una aportación sólo relativamente novedosa, teniendo en cuenta que la reflexión histórico-social estaba ya incorporada dentro de la geografía de las calamidades.

Por otro lado, el hecho de que la geografía de los riesgos haya sido ampliamente estudiada ${ }^{4}$, refuerza el interés de recuperar y analizar la llamada geografía de las calamidades, tarea a la que presta especial atención el presente artículo. Las discusiones académicas, sin embargo, no deben hacernos olvidar el objeto de estudio: las calami-

3 Harlan H. Barrows: «Geography as Human Ecology», Annals of the Association of American Geographers, XIII, marzo 1923, pp. 1-14. («La geografía como ecología humana», en Josefina Gómez Mendoza y otros: El pensamiento geográfico, Madrid, Alianza, 1982, pp. 336-348).

4 Véase por ejemplo, Francisco Calvo García-Tornel: «La geografía de los riesgos», Geo Crítica, n. ${ }^{\circ}$ 54, noviembre 1984, $39 \mathrm{pp}$. Un análisis de las críticas de la geografía radical, en David Sauri Pujol: «Cambio y continuidad en la geografía de los riesgos naturales: la aportación de la geografía radical», Estudios Geográficos, Madrid, XLIX, 191, abril-junio 1988, pp. 257-270. 
dades naturales. Estas continúan causando estragos y sus consecuencias en cuanto a pérdidas de vidas humanas, daños materiales o desorganización social siguen siendo considerables. Sus implicaciones han trascendido el marco de la geografía y son objeto de una amplia atención ${ }^{5}$. Esa ramificación no ha impedido, sin embargo, establecer líneas de consenso, especialmente en el terreno de la causalidad, superando el hecho físico en sí de cada evento, variable según la región del planeta, y poniendo de manifiesto su marcado carácter social. La ordenación que se hace de los desastres tiende también hacia esa unidad. Atendiendo a su naturaleza, Eric L. Jones ha propuesto la siguiente clasificación: geofísica (terremotos, tsunamis, erupciones volcánicas); climática (huracanes, tifones, granizadas, inundaciones, sequías); biológica (epidemias, epizootias, enfermedades en los cultivos, plagas de langosta); y social (guerras, incendios, destrucción de las estructuras fabricadas por el hombre) ${ }^{6}$.

Los propósitos del presente artítulo impiden hacer un análisis particular de cada uno de ellos; sin embargo, estimamos imprescindible una reflexión integradora sobre los mismos si queremos entender los numerosos elementos que confluyen en los eventos calamitosos. Todo lo dicho hasta aquí se nos presenta en un contexto de aparente recrudecimiento de algunos desastres, o por lo menos de permanencia de los mismos, que nos lleva a plantear algunos interrogantes: ¿Han aumentado el número de víctimas y los daños como consecuencia de las catástrofes naturales? ¿La sociedad se ha hecho más vulnerable a las mismas? ¿Por qué se siguen manifestando calamidades que se consideraban prácticamente superadas? ¿Todas las sociedades están afectadas por igual?

5 Véase, Eric L. Jones: «Societal adaptation to disaster», Biology and Human Affairs, vol. 42, 1977, pp. 145-149; "The environment and the economy», en Peter Burke (ed.): The New Cambridge Modern History. XIII. Companion Volume, Cambridge, Cambridge University Press, 1979, pp. 15-42; William H. McNeill: Plagas y pueblos, Madrid, Siglo XXI, 1984, 313 pp.; Alfred W. Crosby: Imperialismo ecológico. La expansión biológica de Europa, 900-1900, Barcelona, Crítica, 1988, 351 pp.; CHAM'S: Enseigner les risques naturels. Pour une géographie physique revisitée, París, Anthropos/Gip Reclus, 1994, 227 pp.; Jean-Paul Gout: Prevention et gestion des risques majeurs. Les risques d'origine naturelle, París, Les Éditions de l'Environnement, 1993, $301 \mathrm{pp}$.

6 Eric L. Jones: El milagro europeo. Entorno, economía y geopolitica en la historia de Europa y Asia, Madrid, Alianza, 1990, 327 pp. La clasificación, en p. 66. 


\section{El retorno de las plagas}

La aparición reciente de brotes de peste bubónica, cólera, malaria o difteria en algunos países que habían erradicado esas enfermedades parecen avalar las tesis más pesimistas. Si esos brotes se han manifestado en Rusia, en otras partes del globo el cólera ha vuelto a convertirse en una auténtica pesadilla, provocando miles de muertos en el sudeste asiático y en varios países amazónicos. La malaria, que en los años sesenta se creía que se podía erradicar, ha vuelto con fuerza; más de 300 millones de personas han podido contraerla durante 1993, especialmente en Africa, sudeste asiático y Amazonas. En total, las enfermedades infecciosas están causando la muerte anual de diecisiete millones de personas, según la Organización Mundial de la Salud. Una nueva epidemia, la del SIDA, ha venido a ennegrecer todavía más el panorama sanitario mundial. Todo esto contrasta con la imagen optimista que se transmitió hace algunas décadas sobre esas enfermedades, desde la ciencia y desde las organizaciones sanitarias, expresada por el premio Nobel de medicina de 1960, M. Burnet: «Los países civilizados del mundo han eliminado ya todas las enfermedades pestilenciales, la peste misma, el cólera, el tifus, la viruela, el paludismo y la fiebre amarilla. La disentería infantil, la escarlatina y la difteria, que fueron origen de la mayor parte de la mortalidad infantil en el siglo xIx, son ahora raras y, en general, extremadamente benignas» ${ }^{7}$.

$\mathrm{Al}$ retorno de esas epidemias hay que añadir plagas que se consideraban controladas, como la langosta, que continúa amenazante en Africa y Asia. Otras calamidades naturales se siguen manifestando con virulencia. Un terremoto reciente en India se ha cobrado alrededor de 20.000 vidas. Igualmente, el balance de años anteriores es espectacular; 1991 se cerró con más de 150.000 víctimas mortales, y 23 millones de personas perdieron su hogar. En el último decenio, las calamidades naturales ocasionaron más de un millón de víctimas y los daños materiales alcanzaron la cifra de 4,5 billones de pesetas. En las dos últimas décadas, los desastres costaron casi tres millones de vidas y afectaron a más de 800 millones de personas en todo el

7 Macfarlane Burnet y David O. White: Historia natural de la enfermedad infecciosa, Madrid, Alianza, 1982, p. 200. 
mundo, según el presidente de la Academia de Ciencias estadounidense Frank Press ${ }^{8}$. Como se ve, las estadísticas recientes son impresionantes; para calibrar su importancia es necesario un análisis comparativo con las de periodos anteriores. Por lo que respecta a nuestro siglo, entre 1900 y 1976 doscientas catástrofes mayores, contando sólo seísmos, ciclones, erupciones volcánicas e inundaciones, provocaron la muerte de más de 5,5 millones de personas, de las que 5,2 millones pertenecían a países asiáticos.

A esas cifras habría que añadir entre 25 y 50 millones de víctimas de la llamada gripe española durante el bienio 1918-1919, o la epidemia de peste que en el periodo 1898-1923 mató entre 11 y 12 millones de personas en India. Las provincias chinas de Shensi, Honan y Kansu padecieron una sequía durante 1928 y 1929 con funestas consecuencias, al morir alrededor de tres millones de personas; en la Unión Soviética, también por sequías y malas cosechas, oficialmente murieron 1,5 millones entre 1932 y 1934, aunque según otras fuentes se acercaron a los cinco ${ }^{9}$.

Aunque se ha afirmado que el avance tecnológico contemporáneo no ha evitado el incremento del promedio de muertes por culpa de las calamidades naturales, e incluso algunos de esos avances son vistos como nuevas amenazas, la historiografía ha mostrado sobradamente la falta de amortiguadores de las sociedades preindustriales frente a aquellos eventos ${ }^{10}$. Por lo que se refiere a los desastres naturales anteriores a 1900, como consecuencia de las sequías del norte de China en el periodo 1876-1879, las muertes por hambre, violencia y enfermedad fueron estimadas entre 9 y 13 millones. Las inundaciones del Hwang Ho (Río Amarillo) en ese mismo país, en setiembre y octubre de 1887, provocaron oficialmente la muerte de novecientas mil personas. En India, en el bienio 1896-1897, cerca de cinco millones murieron por idénticos motivos. En Europa, la mayor hambruna tuvo lugar en Irlanda en el periodo 1846-1851, saldándose

8 Para el terremoto de 30 de setiembre de 1993 en India, Le Monde, 2 octubre 1993. Para el año 1991, El Pais, 14 octubre 1992. Los datos del decenio, en El Pais, 13 octubre 1993. Para las dos décadas, Frank Press: «Romper el ciclo de la destrucción», El Pais, 8 marzo 1990.

9 Datos extraídos de James Cornell: The Great International Disaster Book, Nueva York, Simon \& Schuster, 1979, pags. 185-186.

10 Véase, Vicente Pérez Moreda: La crisis de mortalidad en la España interior. Siglos XVI-XIX, Madrid, Siglo XXI, 1980, 526 pp.

$$
-550-
$$


con alrededor de un millón de muertos y otro millón de emigrantes; los orígenes de la misma se encuentran en una plaga agrícola. Si nos remontamos a fechas anteriores, podemos recordar la Peste Negra, que mató a un tercio de la población europea a mediados del siglo xIV, el terremoto de la provincia china de Shensi en 1556, con 830.000 víctimas, o el de Lisboa de 1755 , con más de 50.000 .

La acumulación de cifras y fechas no debe hacernos olvidar que detrás de las sequías, las inundaciones o las pestes hay sufrimiento, penuria, desnutrición endémica o hambre generalizada, y también que la población sufre los eventos calamitosos de manera desigual. Todo ello evidencia, una vez más, el carácter social de las catástrofes naturales. Estas no son actos divinos exógenos y separados de las elecciones hechas por una sociedad. Su voluntad se expresa en «la densidad de las poblaciones humanas, su nivel de renta y su organización social, los cultivos que siembran y los animales que crían; todo lo cual afecta al grado de vulnerabilidad a conmociones concretas y al impacto que éstas tienen», ha escrito el historiador Eric L. Jones ${ }^{11}$. En el mismo sentido se han manifestado científicos de otras disciplinas; geógrafos y ecólogos, que han advertido que si los procesos físicos son importantes a la hora de enjuiciar los desastres naturales, tanto o más lo son los procesos sociales y económicos. En medicina se ha señalado repetidamente que muchas de las enfermedades epidémicas sólo proliferan en condiciones sociales de pobreza, exceso de población y suciedad.

De este modo, para explicar las enfermedades epidémicas actuales, la Organización Mundial de la Salud ha denunciado la degradación de los sistemas sanitarios en las dos últimas décadas, debido a la negligencia de los gobiernos y al desinterés de la comunidad científica por determinadas enfermedades. Igualmente, la fuerte desorganización social de algunas partes del planeta, o los cambios políticos habidos en la Europa del Este, están en el origen de algunas de las epidemias y plagas actuales. Para entender las situaciones menos recientes, debemos insistir en el carácter social de las calamidades. Como acertadamente ha escrito Nevin S. Scrimshaw, «las frecuentes hambrunas en diversas poblaciones regionales de Europa durante los últimos siglos fueron más el resultado de la pobreza y la desigualdad

11 Eric L. Jones: op. cit., 1990, p. 64.

$$
-551-
$$


social que de una falta real de alimentos» ${ }^{12}$. Sin duda, buena parte de las catástrofes naturales, tanto pasadas como presentes, sólo son inteligibles a la luz del razonamiento de Scrimshaw, es decir, como resultado de la desorganización, la escasez y la distribución desigual de la riqueza, aunque tampoco podamos dejar de lado las insuficiencias científicas sobre algunos de aquellos fenómenos hasta fechas relativamente recientes.

Pero ¿es posible establecer alguna ley sobre las calamidades a partir de los anteriores datos estadísticos? Haciendo abstracción de las posturas deterministas, que afirman la sumisión de las sociedades a las rigideces ecológicas, Eric L. Jones ha mostrado las graves implicaciones que para el desarrollo de las sociedades han tenido históricamente los desastres naturales. Estos gravaron a unas economías más que a otras con gastos generales en términos de pérdidas, daños y desorganización. Jones ha apuntado también que el control de las catástrofes a nivel nacional fue una de las más significativas acciones de los gobiernos europeos desde el siglo xviII. Entre éstas «se incluían la imposición de cuarentenas para frenar la difusión de enfermedades epidémicas entre los seres humanos, el establecimiento de cordons sanitaires para impedir los desplazamientos del ganado infectado, el pago de compensaciones a los granjeros por el sacrificio de rebaños infectados y la aparición de medidas de redistribución de los excedentes de cereal hacia distritos en donde los elevados precios amenazaban con producir hambrunas» ${ }^{13}$.

Este efecto modernizador de la acción estatal por el control de las calamidades, junto a la «notable hazaña de cercenar el poder arbitrario, eliminando así riesgos e incertidumbres, alentando la inversión productiva y promoviendo el crecimiento», explicarían lo que Jones ha llamado el milagro europeo, resultado tanto de las fuerzas que promovieron el desarrollo como consecuencia de la eliminación de sus impedimentos. No obstante, Jones ha señalado también que Europa, en términos geofísicos y climáticos, es más tranquila que la mayoría de las otras partes de la Tierra. Otros autores han establecido,

12 Nevin S. Scrimshaw: «El valor de los estudios contemporáneos sobre alimentación y nutrición para los historiadores», en Robert I. Rotberg y Theodore K. Rabb (comps.): El hambre en la historia, Madrid, Siglo XXI, 1990, p. 370.

13 Eric L. Jones: op. cit., 1990, pp. 17-18. 
como eje explicativo para ese dominio sobre el medio ambiente en el mundo occidental, factores de tipo cultural. Para Lynn White, «la destrucción cristiana del animismo -la idea de que el espíritu existe en la naturaleza aparte del hombre y de los ángeles, caídos o no- y la convicción cristiana de que toda la naturaleza fue planeada divinamente, tan sólo para beneficio del hombre, socavaron las antiguas inhibiciones paganas a la explotación racional de nuestro medio» ${ }^{14}$. Esto estuvo asociado al resurgimiento monástico de la idea judaica de que el trabajo manual era parte esencial de la vida espiritual. Semejante combinación, escribió White, no podía menos que favorecer el desarrollo técnico. De ese modo, después de un periodo de expansión tecnológica de unos mil años, a finales del siglo xv, «Europa contaba no sólo con fuentes de energía mucho más diversificadas que las conocidas en cualquier otra cultura anterior, sino también con un arsenal de medios técnicos para apresar, guiar y utilizar esas energías, que era inmensamente más variado y capaz que el de cualquier otro pueblo del pasado, o que el conocido por cualquier sociedad contemporánea del Viejo o del Nuevo Mundo» ${ }^{15}$.

Apoyándose en argumentaciones semejantes a las de White, George Basalla ha señalado que la idea de que la naturaleza sólo existe para uso humano se encuentra por vez primera en el Génesis, en la narración de la creación; Dios, «tras haber otorgado a Adán y Eva dominio sobre toda planta y animal, les ordenó que sometieran la tierra y la poblaran con su descendencia», se señala en el relato bíblico. De este modo, la sanción religiosa permitió el persistente esfuerzo agresivo de los occidentales por explotar toda posible fuerza y recurso natural, materializado, desde hace ya varios siglos, en el liderazgo tecnológico mundial. En cambio, aquellos pueblos cuya religión les enseñó «a adoptar una actitud más benigna hacia la naturaleza no llegaron a desarrollar la tecnología hasta su máximo potencial» ${ }^{16}$. Además, el punto de vista judeocristiano se vio reforzado en el siglo XVII por los filósofos y ensayistas que, en palabras de Francis Bacon,

14 Lynn White: «Historia y clavos de herradura», en L.P. Curtis Jr. (comp.): El taller del historiador, México, Fondo de Cultura Económica, 1975, pp. 70-87. La cita, en p. 83. Los mismos conceptos en, Lynn White: «The historical roots of our ecologic crisis», Science, 10 marzo 1967, vol. 144, n. ${ }^{\circ} 3.767$, pp. 1.203-1.207.

15 Lynn White: Tecnología medieval y cambio social, Barcelona, Paidos, 1990, p. 146.

16 George Basalla: La evolución de la tecnologia, Barcelona, Crítica, 1991, p. 165. 
pensaban que la naturaleza había sido creada para servir a los asuntos y conveniencias del hombre. En términos parecidos se ha expresado John Passmore, quien ha matizado que fue la tradición cristiana, pero bajo el influjo del pensamiento griego, la que alentó una actitud frente al mundo natural «más de fuente de suministro que objeto de contemplación, dio licencia al hombre para que lo tratase sin reparos, despojó a la naturaleza de su carácter sagrado y vació nuestra conducta para con ella de contenido moral» ${ }^{17}$.

Esa visión tuvo también sus contradicciones. Para una parte de la cristiandad, las calamidades o determinados acontecimientos naturales se convirtieron en pruebas de su ideario fatalista, convirtiéndolos en fenómenos separados y desligados de la sociedad; los votos religiosos o los procesos dirigidos por la Iglesia contra los insectos nocivos, considerados como enviados de Satán, son algunos ejemplos de esos planteamientos irracionales. En otros casos, los desastres naturales parecían ser la constatación del castigo divino frente al pecado de los hombres. Así, el ya mencionado terremoto de Lisboa de 1755 provocó el último gran shock catastrofista en la mentalidad colectiva occidental y golpeó con fuerza las conciencias cristianas ${ }^{18}$.

La superación de los postulados providencialistas no empezó a producirse realmente hasta la Ilustración. Esta consiguió, bien que poco a poco, enajenarse de la cultura teológica al poder apoyarse en la nueva autoridad que le confería el discurso científico y que proclamaba la soberanía de la razón ${ }^{` 19}$. Por otro lado, un fruto moderno del dominio político y económico occidental fue la aparición de las preocupaciones científicas relacionadas con las calamidades. Ya hemos

17 John Passmore: La responsabilidad del hombre frente a la naturaleza, Madrid, Alianza, 1978, p. 35.

18 Las relaciones entre algunas calamidades naturales y los votos religiosos son estudiadas en, W. A. Christian Jr.: Religiosidad local en la España de Felipe II, Madrid, Nerea, 1991, 352 pp. Los procesos contra los insectos en, H.L. Blanchon: L'art de détruire des animaux nuisibles (París, 1809), recogido por A.S. Balachowsky: La lutte contre les insectes. Principes. Méthodes. Applications, París, Payot, 1951, p. 13. Sobre el terremoto de Lisboa en particular, y sobre las relaciones entre el pensamiento occidental y la naturaleza hasta la Ilustración, véase Clarence J. Glacken: Huellas en la playa de Rodas. Naturaleza y cultura en el pensamiento occidental desde la Antigüedad hasta finales del siglo XVIII, Barcelona, Ediciones del Serbal, 1996, pp. 476 ss.

19 Véase por ejemplo, Luis Urteaga: La tierra esquilmada. Las ideas sobre la conservación de la naturaleza en la cultura española del siglo XVIII, Barcelona-Madrid, Serbal/ CSIC, 1987, $221 \mathrm{pp}$. 
mencionado las imbricaciones entre determinadas ramas de la ciencia, como la epidemiología y la entomología aplicada, con el imperialismo europeo en el tránsito del siglo XIX al Xx. En este contexto debemos considerar el surgimiento de las primeras reflexiones epistemológicas sobre la geografía de las calamidades naturales, llevadas a cabo gracias a un proyecto apoyado por la Sociedad de Naciones durante la tercera década de la presente centuria.

\section{La geografía de las calamidades}

"iQue la Humanidad se interese firme, resueltamente, en estas cuestiones y consagre a ellas sus esfuerzos en vez de derrocharlos en guerras tan mortales como inútiles!» exclamó Ricardo Beltrán al finalizar la conferencia que sobre la geografía de las calamidades leyó en la Escuela de Estudios Superiores del Magisterio, el 18 de diciembre de $1927{ }^{20}$. Ricardo Beltrán y Rózpide (1852-1928), destacado miembro de la Real Sociedad Geográfica de Madrid, tomó la palabra para inaugurar la Asamblea de los Profesores de Escuelas Normales. Beltrán y Rózpide había sido secretario del Congreso español de Geografía colonial y mercantil en 1883, presidente de la sección de emigración del Congreso africanista de Zaragoza en 1908 y, desde 1909, catedrático de Geografía en la Escuela Superior de Magisterio. En la conferencia de 1927, Ricardo Beltrán pretendía propagar el primer proyecto mundial de prevención de las calamidades naturales, una iniciativa del italiano Giovanni Ciraolo, presidente de la Cruz Roja internacional. El proyecto, apoyado por el Consejo de la Sociedad de Naciones, planteaba confeccionar un atlas universal de calamidades naturales y había puesto en marcha la Unión internacional de Socorro. Esta había sido creada gracias a la iniciativa de más de 40 Estados, básicamente europeos. Entre los firmantes del Acta final fi-

20 Ricardo Beltrán y Rózpide: La Unión internacional de Socorro y la geografía de las calamidades, Publicaciones de la Real Sociedad Geográfica, Imprenta del Patronato de Huérfanos de Intendencia e Intervención Militares, 1928, 19 pp. La cita está en la última página. Sobre Ricardo Beltrán y la geografía de las calamidades en la Revista de Escuelas Normales, véase Clemente Herreno Fabregat: «La geografía en la Revista de Escuelas Normales (1923-1936)», Estudios Geográficos, LVII, 222, enero-marzo 1996, pp. 31-65. 
guraron Alemania, Bélgica, Bulgaria, Colombia, Cuba, Danzig, Ecuador, España (a reservas de ratificación), Guatemala, Italia, Mónaco, Polonia y Uruguay. Por otra parte, el atlas debía recoger de cada país y para cada calamidad una lista cronológica de las catástrofes con indicación de las causas, regiones afectadas, víctimas humanas y daños materiales; todo ello permitiría establecer, según Beltrán y Rózpide, el «coeficiente de frecuencia e intensidad» de cada calamidad. Para su estudio no bastaban los hechos observados, hacían falta datos, «y a obtenerlos mediante labor continua de individuos y de centros y organismos establecidos al efecto tiende la geografía de las calamidades en su doble aspecto de geografía de observación y descriptiva, y de geografía explicativa, científica, que busca la razón de los hechos y la manera constante de producirse éstos, es decir, las leyes» ${ }^{21}$.

Por último, y previa exposición de una visión organicista, señalaba que el ideal de prever, prevenir y evitar las calamidades sólo podría llegar a realizarse de modo completo cuando el hombre hubiese descubierto «las funciones de la Tierra». No era la primera vez que Beltrán tomaba la palabra para hablar sobre la geografía de las calamidades. En el Boletín de la Real Sociedad Geográfica de 1924 había fijado ya los objetivos de la disciplina. Entreviendo el marcado carácter social de los fenómenos calamitosos, decía que era necesario poder determinar las zonas donde aparecían los desastres, «que son siempre consecuencia de fuerzas naturales, secundadas a veces por factores humanos de orden económico o sociológico. Un gran número de calamidades se producen casi siempre en las mismas regiones y alcanzan a las mismas poblaciones» ${ }^{22}$. Un año antes, Raoul Montandon había publicado A propos du projet Ciraolo. Une carte mondiale de distribution géographique des calamités ${ }^{23}$, en el que relataba la experiencia del presidente de la Cruz Roja internacional, cuya familia había sufrido gravemente el terremoto de Mesina de 1908, y que llevó a Ciraolo a organizar la solidaridad contra los efectos de las catástro-

21 Ricardo Beltrán y Rózpide: op. cit., 1928, p. 8.

22 El artículo era reproducido, en parte, en el n. 2 de Matériaux pour l'Étude des Calamités, Ginebra, Société de Géographie, julio-setiembre 1924, pp. 167-169.

23 Raoul Montandon: A propos du projet Ciraolo. Une carte mondiale de distribution géographique des calamités, (Extrait de la Revue Internationale de la Croix-Rouge, n. ${ }^{\circ} 52$, abril 1923, pp. 271-344), Ginebra, 1923, 71 pp.

$$
-556-
$$


fes en la conferencia internacional de aquella organización en 1921. Montandon estudiaba las calamidades que debían ser tenidas en cuenta; los terremotos, las erupciones volcánicas, los tsunamis, los huracanes, ciclones y tifones, las sequías, las tempestades de nieve, las inundaciones, los incendios, las invasiones de langosta, las hambrunas y las enfermedades. Algunas iban acompañadas de mapas, extraídos de las obras del geógrafo Emmanuel de Martonne y del vulcanólogo Fernand de Montessus de Ballore. Por otro lado, Montandon acudía a Émile Littré para definir el concepto de calamidad, señalando que las pérdidas en vidas humanas y los daños materiales, junto a la frecuencia del fenómeno, debían de ser los determinantes a la hora de establecer cualquier clasificación entre ellas. Como muestra de lo que debía hacerse para cada calamidad, incluía una lista cronológica de varios centenares de invasiones de langosta en distintas regiones del globo, que le servía para confeccionar el primer mapa mundial de esa plaga.

Ese afán positivista se reflejó ampliamente en la obra más notable de Montandon, la revista Matériaux pour l'Étude des Calamités, patrocinada por la Société de Géographie de Ginebra, de la que fue socio desde 1909. Raoul Montandon (1877-1950) estudió arquitectura, y siendo joven se sintió atraído por la prehistoria, la etnografía y la arqueología. También fue miembro de otras asociaciones suizas y extranjeras, entre ellas la Société de Géographie de Marsella y la American Geographical Society de Nueva York. Giovanni Ciraolo escribió con motivo de su desaparición que «fue curioso de todas las ciencias, y consideraba su difusión como una práctica de higiene espiritual» ${ }^{24}$. Por otro lado, el nacimiento de la revista fue saludado por destacados miembros de la comunidad geográfica; en su primer número encontramos las salutaciones de G. Grandidier, secretario de la Société de Géographie de París; de Jacques Léotard, de la de Marsella; de F. Shkalsky, de la Sociedad Rusa de Geografía; y de Eugen Oberhummer, presidente de la Geographischen Gesellschaft de Viena. En ese ejemplar, Montandon, después de apuntar que su creación estaba relacionada con el proyecto del atlas mundial de distribución geográfica de las calamidades, acababa di-

24 Revue pour l'Étude des Calamités. Bulletin de l'Union internationale de Secours, n. ${ }^{\circ} 2829$, enero 1950-diciembre 1951, p. 99. 
ciendo que la «reunión de elementos estadísticos juiciosamente interpretados permitirá descubrir en el futuro algunas de las leyes a las que obedecen esos fenómenos recurrentes y periódicos; y cuando conozcamos esas leyes estaremos mejor preparados para defendernos y para limitar las consecuencias desastrosas de las catástrofes tan diversas que asuelan a la humanidad» ${ }^{25}$.

La revista contó desde su primer número con una sección documental sobre catástrofes y otra de bibliografía, en las que aparecería con gran frecuencia la pluma de Montandon, que realizó un trabajo ingente de divulgación de obras y acontecimientos relacionados con la geografía de las calamidades. Por esas fechas, en 1925, Raoul Montandon participó en el Congreso internacional de Geografía de El Cairo, realizando un llamamiento a los geógrafos y geofísicos para el estudio coordinado y sistemático de lo que debía denominarse geografía de las calamidades, y dando a conocer el proyecto de la UIS. Este último, apuntó, tendía a transformar la noción de la ayuda caritativa a los siniestrados por el de «un principio de derecho internacional al que ningún país civilizado podría sustraerse» ${ }^{26}$. Para que el proyecto fuese adelante se debía confeccionar el atlas ya mencionado, con la ayuda de geógrafos, historiadores y otros científicos. De cada calamidad, afirmó, debían realizarse mapas cada cinco lustros. La superposición de los documentos cartográficos permitiría determinar las regiones sujetas a cada calamidad. Montandon acabó su intervención diciendo que era necesario seguir creando comisiones contra las calamidades, a semejanza de las que ya existían en Italia y Hungría, o de las que se estaban formando en Estados Unidos, Brasil y España. Para sostener la creación de la UIS, Montandon publicó artículos periodísticos, e incluso una obra con ese único fin, en la que se refería al

25 Raoul Montandon: «La Géographie des calamités», Matériaux pour l'Étude des Calamités, n. $^{\circ}$, abril-junio 1924, Société de Géographie, Ginebra, pp. 9-20. La cita en p. 20. El proyecto del atlas también se publicó en: Le projet Ciraolo et la carte mondial de distribution géographique des calamités. Communication faite au Congrès de l'Association des Sociétés suisses de géographie, session de Berne, octobre 1923, Ginebra, Kundig, 1924, $11 \mathrm{pp}$.

${ }_{26}$ Raoul Montandon: De la coordination des recherches scientifiques pour l'étude des calamités. Communication faite au Congrès international de Géographie du Caire. 1-9 avril 1925, Macon, Imprimerie Protat Frères, 1925 , 15 pp. La cita en p. 6; la cursiva es del original. 
apoyo mutuo y a la fraternidad universal como las ideas fuerza que debían inspirar a la geografía de las calamidades ${ }^{27}$.

Matériaux publicó cuarenta números, recogió en su seno los diversos temas de la geografía de las calamidades, visitó todos los continentes, realizó estudios regionales e internacionales, colaborando, entre otros, geógrafos, médicos, ingenieros y geólogos. Entre las aportaciones de los primeros hay que destacar la de W. Severit sobre la importancia de los terremotos desde el punto de vista de la geografía humana, en la que estudiaba la naturaleza de los seismos; su reparto (incidencia, gravedad y daños); sus efectos sobre la naturaleza, los hombres y las obras humanas; y las medidas de protección y precaución contra esos fenómenos. Otras aportaciones desde la geografía fueron las de Norbert Fischer, del Geographischen Institute de la Universidad de Rostock, las del profesor de Geografía en la Universidad de Würzburg, Karl Sapper, y las de los profesores George T. Renner, de la Columbia University, y Stephen S. Visher, de Indiana ${ }^{28}$. Por materias, destacaron los trabajos dedicados a las inundaciones, del ingeniero topógrafo neoyorquino Oscar Messerly ${ }^{29}$; a los terremotos, del director del Institut de Physique du Globe de Estrasburgo, Edmond Rothé ${ }^{30}$; a

27 Para sostener la creación de la UIS, Raoul Montandon: Pour une coordination de l'effort scientifique dans la lutte contre les calamités. Mémoire rédigé à l'occasion de la Conférence diplomatique chargée de conclure l'accord nécessaire à la création de l'Union internationale de Secours, Ginebra, Société de Géographie, 1927, 118 pp.

28 W. Severit: «Die Anthropogeographische Bedeutung der Erdbeden», n. ${ }^{\circ}$ 30-31, 1933, pp. 99-218; Norbert Fischer: «Die Tropischen Wirbelstürme und das wirtschaftsleben des menschen», n. ${ }^{\circ} 12$, eneromarzo 1927, pp. 283-303; Karl Sapper: «Schutzmassregeln bei vulkanausbrüchen», n. ${ }^{\circ}$ 6, julio-setiembre 1925, pp. 99-118; George T. Ren ner, Jr.: "The Sudan: a tropical famine area», n. $^{\circ} 11$, octubre-diciembre 1926, pp 187-205; Stephen S. Visher: «Tropical cyclones as calamities», n. ${ }^{\circ}$ 3, octubre-diciembre 1924, pp. 195-217.

29 Oscar Messerly: «L'inondation du bassin du Mississippi en avril et mai 1927», n. ${ }^{\circ}$ 15, octubre-diciembre 1927, pp. 209-230; «Les inondations aux États-Unis en novembre $1927 »$, n. $^{\circ} 17$, abril-junio 1928 , pp. 42-50. Messerly también publicó: «Le cyclone de Camaguey (Cuba)», n. ${ }^{\circ}$ 30-31, 1933, pp. 219-225. Otros artículos sobre las crecidas fueron los de E.P. Pouichet: "Les crues de l'embouchure de la Néva» n. ${ }^{\circ}$ 5, abril-junio 1925 , pp. 3-36; H. Reck: «Hochwasserkatastrophen», n. ${ }^{\circ}$ 9, abril-junio 1926, pp. 48-74; Ludwig Brandl: «Ueberschwemmungs-katastrophen an der oesterreichischen Donau», n. 18, julio-setiembre 1928, pp. 113-128; Maurice Pardé: «La grande crue du Rhone en novembre $1935 »$, n. $^{\circ} 36,1935$, pp. 99-122.

30 Edmond Rothé: «Les tremblements de terre en France», n. ${ }^{\circ}$ 9, abril-junio 1926, pp. 3-47. Rothé había publicado Le tremblement de terre, París, Librairie Félix Alcan, 1925, XXXIV-248 pp. Otros trabajos publicados en la revista sobre sismología fueron 
la vulcanología y a las sequías; y a las epidemias y plagas de langosta ${ }^{31}$.

En setiembre de 1937, coincidiendo con la Exposición internacional de París, tuvo lugar en esa ciudad la primera Conferencia internacional contra las calamidades naturales. Los orígenes y fines de la reunión los presentó Raoul Montandon. Este repitió lo ya dicho sobre el mapa de distribución de las grandes calamidades y sobre las comisiones nacionales. Estas últimas habían sido ya creadas en once países: Italia, Hungría, Francia, Suiza, Bélgica, Austria, Bulgaria, Grecia, Checoslovaquia, Portugal y Chile. La comisión española estaba formada pero la guerra había impedido su presencia en la reunión. La convocatoria de la conferencia había partido de la comisión francesa, de la que formaba parte el propio Montandon; otros de sus miembros destacados eran Paul Vayssière, E. Roubaud y Edmond Rothé. Esta comisión había desarrollado gran actividad, y sus numerosas actividades habían aparecido reflejadas en Matériaux ${ }^{32}$. La conferencia se dividió en secciones, destacando la de vulcanología y sismología, que debía ser presidida por el director del Institut de Géographie de París, Emmanuel de Martonne, aunque finalmente no participó en la reunión. Entre las comunicaciones de esta sección figuraron las del presidente de la Asociación Sismológica internacional, N.H. Neck, y las de A. Née, E. Rothé, Karl Sapper y W. Severit. Otra de las secciones destacadas fue la de zoología, con los trabajos de E. Roubaud, Boris P. Uvarov y Paul Vayssière ${ }^{33}$. La sesión de

los de Louis de Launay: "Tremblements de terre et volcans», . $^{\circ} 1$, abril-junio 1924 , pp. 21-44; T. A. Jaggar: «Earthquake insurance», n. ${ }^{\circ}$ 7, octubre-diciembre 1925, pp. 191 217; A. Hée: «La séismicité dans l'Afrique du Nord», n. ${ }^{\circ}$ 28, 1931-1932, pp. 291-337.

31 Arcangelo Ilvento: «Notes sur une carte des épidémies dans les pays avoisinant la Méditerranée», n. ${ }^{\circ}$ 6, julio-setiembre 1925, pp. 119-150; E. Roubaud: «La fièvre jaune dans le monde et les méthodes modernes d'action contre ce fléau», n. ${ }^{0} 13$, abril-junio 1927, pp. 50-74; W. Frantzen: «Die geographischen Vertreitung und wirtschaftsgeographische Bedeutung der Tsetselfliege», n. ${ }^{\circ}$ 16, enero-marzo 1928, pp. 293-338. Para la langosta, Paul Vayssière: «Le problème acridien et sa solution internationale», $n .{ }^{\circ} 2$, julio-setiembre 1924, pp. 122-158.

32 Première Conférence internationale pour la protection contre les calamités naturelles. Paris, 13-17 septembre 1937, Publié par la Commission française d'études des calamités avec le concours de l'Union internationale de Secours, 1938, 531 pp. La intervención de Montandon se tituló «Origine et but de la conférence», pp. 53-63.

${ }_{33}$ N. H. Neck: «Statement regarding Methods or reducing or preventing earthquake Damage in the United States»; A. Née: «Rapport sur la construction aséismique et sur l'assurance contre les tremblements de terre»; E. Rothé: «Les tremblements de te- 
clausura tuvo lugar el 17 de setiembre de 1937 y fue presidida por el ministro francés de las Colonias, Marius Moutet. Entre sus resoluciones figuró que la UIS se hiciese cargo de Matériaux y que se examinase la creación de una comisión supranacional permanente de protección contra las calamidades. Asimismo se propuso extender la red de comisiones nacionales, y celebrar otra conferencia internacional en un plazo máximo de cinco años.

Matériaux pasó a denominarse Revue pour l'Étude des Calamités. Bulletin de l'Union internationale de Secours. En la introducción de su primer número, Raoul Montandon afirmaba que gracias al apoyo de la comunidad científica y de la UIS estaba naciendo una verdadera ciencia de las calamidades. Dos elementos de reflexión se imponían en esos momentos, apuntaba: el principio del seguro, extendido a los daños causados por las fuerzas naturales, y los aspectos sociológicos del tema, que comprendían un mejor conocimiento de las reacciones que en la población provocaban las grandes catástrofes. La nueva publicación continuó los trabajos de. Matériaux sobre los desastres naturales; sin embargo, la guerra mundial la hirió gravemente. La fe de Raoul Montandon en su proyecto parece ser que también se resintió. Durante la conflagración, la revista pasó a ser anual; más tarde, bianual. La desaparición de Montandon en 1950, y de Giovanni Ciraolo en 1953, agotó casi definitivamente un proyecto de claro contenido filantrópico. La revista, sin embargo, continuó publicándose hasta la década siguiente, pero sin el ímpetu de la primera etapa. Entre los trabajos de la segunda época destacaron los de Maurice Pardé, Charles Bois, Sophie Kaczorowska, Hoyt Lemons, Paul Vayssière ${ }^{34}$ y Camille Gorgé ${ }^{35}$, miembro del comité ejecutivo de la UIS. La Revue de-

rre, éruptions, vagues de fond»; Karl Sapper: «Der Kampf gegen die vulkanischen Gewalten»; W. Severit: «L'importance des tremblements de terre au point de vue de la Géographie humaine». En zoología, E. Roubaud: «La transmission de la fièvre jaune dans les pays extra-tropicaux»; B. P. Uvarov: «Locusts as a World Problem»; P. Vayssière: «La coordination et la coopération internationale dans la lutte contre les fléaux des cultures».

34 Paul Vayssière: «Le problème acridien», n. ${ }^{\circ}$ 25, enero-diciembre 1947, pp. 3-13; «Le problème acridien sur le continent africain», n. ${ }^{\circ} 32$, enero-diciembre 1954, pp. 23-36; «Le criquet nomade et le criquet pelèrin en $1959 », n{ }^{\circ} 36$, enero-diciembre 1959 , pp. 38-57.

35 Camille Gorgé: «Création d'un centre international de recherches et de coordination en matiére de calamités naturelles», n. ${ }^{\circ}$ 7, julio-agosto 1939, pp. 200-218. Gorgé era autor también de: La Unión internacional de Socorros, sus origenes, su fin, sus medios, su porvenir, Ginebra, Unión internacional de Socorros, 1938, 56 pp. 
sapareció en 1966, haciéndose cargo de ella la UNESCO, que llegó a publicar diez números con el título Résumé Annuel d'Informations sur les "Catastrophes Naturelles», dejando de publicarse definitivamente en 1975.

Paralelamente a la geografía de las calamidades, ya lo hemos señalado, en Estados Unidos empezó a desarrollarse una línea de trabajo con importantes conexiones con el proyecto apadrinado por Raoul Montandon. Aunque sin espacio material en este artículo, no podemos dejar de citar algunos de sus nombres y trabajos destacados. El primero, Harlan H. Barrows, autor del discurso para la Association of American Geographers en diciembre de 1922 considerado como punto de partida de lo que algunas décadas después empezó a conocerse como geografía de los riesgos. Más tarde, Gilbert F. White, alumno de Barrows, desarrolló ya plenamente la disciplina; otros miembros destacados fueron Ian Burton y Robert W. Kates ${ }^{36}$. Sin embargo, las primeras críticas a este modelo no tardaron en llegar ${ }^{37}$; en general, desde los nuevos planteamientos, denominados radicales, se señalaba la falta de perspectiva histórica de la geografía de los riesgos, su pobreza teórica, su insensibilidad a las estrategias de adaptación de las culturas indígenas y su ignorancia de los trabajos llevados a cabo en sociología y en antropología. Las reflexiones de la geografía radical habrían venido así a llenar ese hueco ${ }^{38}$.

Por nuestra parte, debemos señalar que si bien es acertado este planteamiento por lo que respecta a la geografía de los riesgos como disciplina académica, creemos fundamental la tarea de recuperación histórica de la llamada geografía de las calamidades. Sin ese ejercicio es difícil entender algunos de los planteamientos más significati-

36 Véase Gilbert F. White (ed.): Natural hazards. Local. National. Global, Nueva York, Oxford University Press, 1974, XVI-288 págs; Robert W. Kates e Ian Burton (eds.): Geography, resources and environment. Volume II: Themes from the work of Gilbert F. White, Chicago, The University of Chicago Press, 1986, XVI + 376 pp.

37 La obra crítica incial más significativa fue la de K. Hewitt (ed.): Interpretations of calamity from the viewpoint of human ecology, Boston, Allen \& Unwin Inc., 1983, XIV-304 pp.

38 Véase, por ejemplo, Lloyd Timberlake: Africa in crisis: the causes, the curses of environmental bankruptcy, Filadelfia, New Society Publishers, 1986. Michael Watts: Silent violence. Food, famine and peasantry in Northern Nigeria, Berkeley, University of California Press, 1983. Véase también, Jacque Emel y Richard Peet: «Resource management and natural hazards», en R. Peet y N. Thrift (eds.): New models in geography. The political-economy perspective, vol. 1, Londres, Unwin Hyman, 1989, pp. 49-76. 
vos que se han llevado a cabo en la presente centuria frente a los eventos calamitosos. Por lo que sabemos, la geografía de las calamidades avanzó algunos de los presupuestos que ahora se presentan como novedosos, en especial los que se refieren al carácter social de las catástrofes naturales. Lo cierto es que los dos modelos de investigación, es decir, la geografía de las calamidades y la de los riesgos, junto al trabajo de otras disciplinas, han ayudado en las últimas décadas a crear un marco de nuevas sensibilidades frente a las catástrofes naturales. Un claro ejemplo es la declaración de la presente década como Decenio Internacional para la Reducción de los Desastres Naturales, hecho que trasciende el marco de la ciencia y tiene unas fuertes implicaciones de carácter polític ,-económico.

RESUMEN: Los desastres naturales y la geografía contemporánea. La geografía contemporánea empezó a integrar los eventos calamitosos en sus reflexiones epistemológicas gracias a la geografía de las calamidades, cuyas primeras formulaciones aparecieron hacia 1920, de la mano de Raoul Montandon. La obra más importante de éste fue la revista Matériaux pour l'Étude des Calamités. La otra reflexión epistemológica importante sobre las calamidades naturales se desarrolló en Estados Unidos, gracias a la iniciativa de los alumnos de Gilbert F. White. En la década de los sesenta, I. Burton, R.W. Kates y el mismo White, empezaron a plantear la llamada geografía de los riesgos. Esta empezó pronto a ser calificada de tecnocrática por la llamada geografía radical, como resultado de la aplicación del análisis marxista. La disciplina recuperaba así algunos de los presupuestos iniciales de la geografía de las calamidades; aquellos que ponían énfasis en el carácter social de las catástrofes naturales. Estos modelos de investigación, junto al trabajo en otras disciplinas, han ayudado a crear un marco de nuevas sensibilidades frente a las mismas.

Palabras Clave: Desastres naturales. Retorno de las plagas. Geografía de las calamidades. Geografía de los riesgos.

AbstRact: Natural disasters and Contemporary geography. The contemporary geography began to integrate the disasters events in its epistemological reflections due to the geography of calamities. Its first formulations were published in 1920, by Raoul Montandon. Raoul Montandon's most important work was Matériaux pour l'Étude des Calamités. The other important epistemological reflection about natural disasters expounded in the U.S.A., by the followers of Gilbert F. White. In the sixties I. Burton, R. W. Kates and White himself, began to implant the so called geography of the risks. This geography will be called technocratic geography by the radical geography that applied the marxist analysis. The discipline recovered some of the initial presupositions of the geography of calamities, those that emphasized the social nature of natural disasters. Those patterns of research, combined with the work in other disciplines, have helped to create a framework of new sensitivities toward the disasters.

KEY wORDS: Natural disasters. The return of the plague. Geography of calamities. Geography of risks. 
RÉSUMÉ: Les désastres naturels et la géographie contemporaine. La géographie contemporaine a commencé à intégrer les faits calamiteux dans leurs réflexions épistémologiques à partir de la géographie des calamités dont les premières formulations son apparues vers 1920, de la main de Raoul Montandon. Une de ses oeuvres les plus importantes a été Matériaux pour l'Étude des Calamités. L'autre réflexion épistemologique importante sur les calamités naturelles s'est développée aux États-Unis à partir de l'iniciative des élèves de Gilbert F. White. Dans les années 60, I. Burton, R.W. Kates et White commenceront à poser la géographie des risques. Celle-ci fut qualifiée rapidement de technocrate par la géographie radicale, résultat de l'application de l'analyse marxiste. La discipline récupérait ainsi quelques principes iniciaux de la géographie des calamités; par exemple ceux qui ponaient l'accent sur le caractère social des catastrophes naturelles. Ces modéles d'investigation et le travail efectué dans d'autres disciplines ont aidé à créer un marc de nouvelles sensibilités en relations aux mêmes.

Mots CLÉs: Désastres naturels. Retour des plagues. Géographie des calamités. Géographie des risques. 